\title{
Correction to: The location and composition of Group 3 of the periodic table
}

\author{
René E. Vernon ${ }^{1}$ (i) \\ Published online: 12 October 2020 \\ (c) Springer Nature B.V. 2020
}

\section{Correction to: Foundations of Chemistry https://doi.org/10.1007/s10698-020-09384-2}

In the original publication of the article, the author has identified four belated corrections which are listed below.

1. In the reference list, the book title of the author Cotton, $S$ was incorrect. The correct reference should read "Cotton, S.: Lanthanide and actinide chemistry. Wiley, Chichester (2006)"

2. In the last paragraph of section "IX. f-block integrity", the sentence " and at E123-125(?) for $5 \mathrm{~g}$ (Eugen Schwarz, pers. comm. 8 Dec 2019)" should read as "...........and at E123-125(?) for 5g (Dogon \& Pyykkö 2017)."

The new reference is as follows:

Dognon, J-P., Pyykkö, P. Chemistry of the $5 \mathrm{~g}$ elements: Relativistic calculations on hexafluorides. Angew. Chem. Int. Ed. 56, 10132-10134 (2017)

3. The name "Ligshitz" throughout the article should read as "Lifshitz".

The original article has been corrected.

Publisher's Note Springer Nature remains neutral with regard to jurisdictional claims in published maps and institutional affiliations.

The original article can be found online at https://doi.org/10.1007/s10698-020-09384-2.

René E. Vernon

rene@webone.com.au

1 Kingston, ACT, Australia 